Proceedings of the 2011 Winter Simulation Conference

S. Jain, R.R. Creasey, J. Himmelspach, K.P. White, and M. Fu, eds.

\title{
SIMULATION EDUCATION - SEVEN REASONS FOR CHANGE
}

\author{
Allen Greenwood \\ Mississippi State University \\ Industrial \& Systems Engineering \\ Mississippi State, MS 39762, USA
}

\author{
Malcolm Beaverstock \\ Flexsim, Inc. \\ PO Box 5 \\ Mobile, AL 36590, USA
}

\begin{abstract}
Simulation, once the magic wand of a simulation professional, has the opportunity to become a common tool for analyzing and solving real-world problems in today's fast paced, dynamic environment. Graduating students will have to be prepared to take advantage of that opportunity. Applying simulation today isn't like completing an exercise in a traditional text. Even case studies don't teach students how to actually solve real-world problems. There are good reasons to consider a change. The book Applied Simulation Modeling and Analysis using Flexsim, in use for two years, supports a fresh approach for teaching simulation. Its organization, application techniques, blending of theory with practice, and the introduction of topics not normally covered in traditional texts make it different. This book is all about applying simulation.
\end{abstract}

\section{INTRODUCTION}

To be a factor in today's economically-driven environment, simulation must earn its way by providing a value-added contribution to solving real world problems. Traditional approaches for teaching simulation courses tend to follow a well-worn path utilizing textbooks that focus on simulation theory and software programming. Less emphasis is given to application techniques and methods.

Indeed the challenge facing educators today is how to cover a blend of theory, practice, and problem solving techniques in an already crowded class schedule. The book Applied Simulation Modeling and Analysis using Flexsim was developed by teachers and practitioners to address those challenges.

Change is never easy, especially in an education environment. However, there are seven reasons to review current simulation education objectives and the supporting textbooks that are available.

\section{SEVEN REASONS FOR CHANGE}

\subsection{The Role of Simulation has Changed}

Simulation started as a technology practiced by experts who understood and could utilize the software applications. Companies once employed large groups to carry out simulations. However, when the economy first began to tighten about 20 years ago, the simulation groups were among the first to go. Managers failed to see the value in simulations versus good engineering experience - especially if simulations were created for systems where there was no defined problem to solve.

Seeing the marketplace changing, simulation software providers began to utilize computer technology to simplify the use of their programs. As a result, the technology that used to be the realm of experts is starting to be recognized as a tool that's available to a much wider audience for analyzing and solving real-world problems. 


\section{Greenwood and Beaverstock}

From manufacturing to container terminals, from airport security to emergency response, from mining to health care, simulation technology is making a difference. Leaders in all sectors of our economy are beginning to realize the value of simulation - not so much as a technology but as a means to solve problems.

Whether it's supporting lean manufacturing concepts, improving the efficiency of operations, or providing insight into new designs - simulation is expected to help. In this fast-paced economic environment results from simulation are expected quickly and accurately. Staff members, and especially new hires, are expected to "hit the ground running" when called upon to use simulation. Long learning curves, and the need for retraining, are not acceptable. Simulation is earning a place in decision support systems as shown in Figure 1. This role, as part of an integrated system, means that the emphasis is on the ability to apply simulation technology - not just to know about it.

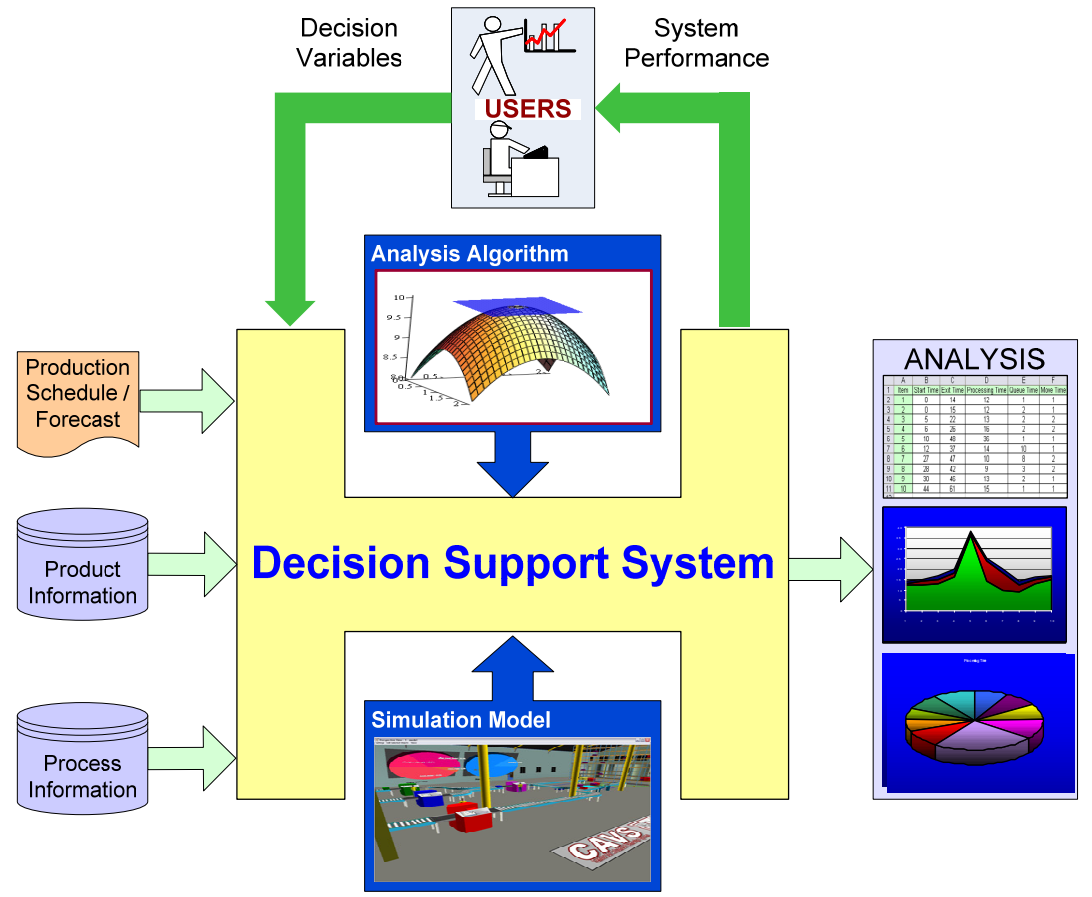

Figure 1: Simulation's role in a decision support system

Therefore, it's important that, when discussing the background of simulation in a textbook, the material is presented in a way that reflects how simulation is applied. Reviewing simulation history should involve the reasons why simulation was used and the resulting benefits. Chapters 1 and 2 in Applied Simulation Modeling and Analysis using Flexsim discuss simulation from an application perspective and include economic justification areas as shown in Figure 2.

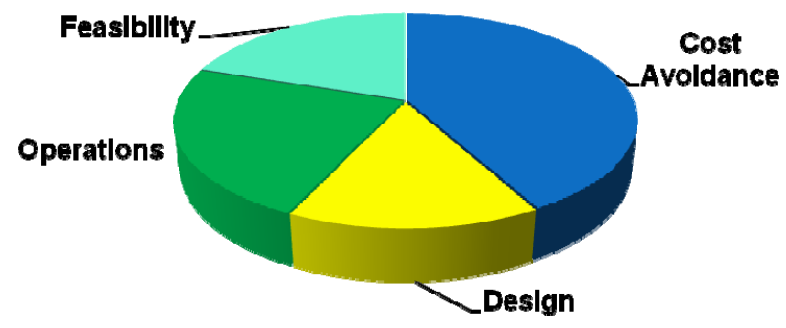

Figure 2: Simulation justification areas 


\section{Greenwood and Beaverstock}

\subsection{Students will be Involved in Simulation But Not at the Same Level of Expertise}

During their careers, students will very likely become involved with simulation to some degree. They may use simulation occasionally to address specific issues or analyze an operation. Such Occasional users may include a manager who authorizes or directs the use of simulation, someone who runs pre-built simulations to analyze strategic decisions, a business unit leader, marketing person, or operations person such as team leader. The Occasional user typically has much more knowledge of the purpose and domain of the simulation than of the simulation application itself.

People who have a problem-solving role as their primary focus may find themselves using simulation as a tool that is available to help with analysis and decision making. These Intermediate users may be project engineers or people involved with logistics, research, or business unit functions. The Intermediate users will work with pre-built models but they can also modify simulations or build their own simulations using standard logic functions provided by the simulation software. Software such as Flexsim allows Intermediate users to build complex logic without any programming.

Finally, some students will continue to master both the techniques of applying simulation as well as becoming proficient with the more advanced features of the simulation software. Since Flexsim has a true object-oriented architecture, Advanced users can easily make use of its extensive functionality. The Advanced user will build extremely complex simulations and will mentor other users on application techniques. An estimate of the percent of simulation users at the various levels are shown in Figure 3.

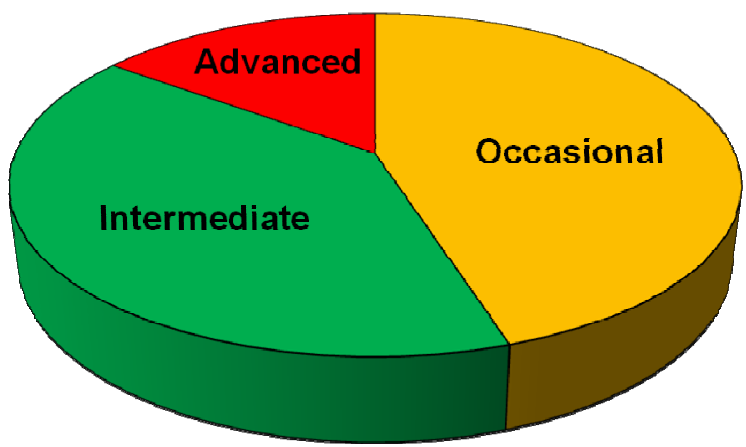

Figure 3: Projected simulation user levels

As simulation education works to address the needs of the various users, a textbook that is already organized to address those levels provides an advantage. Rather than the traditional textbook organization of a section providing background information, followed by sections dedicated to building models and reviewing case studies, Applied Simulation Modeling and Analysis using Flexsim is organized according to the material that is relevant to the user levels themselves.

\subsection{Applying Simulation in the Real World isn't Like Doing a Problem in Class}

Students who think that the practical application of simulation will be like a traditional textbook problem (or even a case study), where the problem is completely spelled out with all the relevant data attached, will be ill-prepared to address a real problem.

Since the emphasis in the work environment is on problem solving, someone approaching a problem may have to first decide if simulation is even required. If it is, they will then have to address questions such as: what should be simulated and to what level of detail, what is the objective, what are the important metrics, what assumptions are involved, and how should the results be presented. Most importantly, the work will involve considerable interactions with other people and even possibly involve a team effort. 


\section{Greenwood and Beaverstock}

To address this issue, Chapter 4 of Applied Simulation Modeling and Analysis using Flexsim is dedicated to the professional practice of simulation. Simulation will only continue to expand as an important tool if the application work is carried out in a professional manner that builds confidence in the technology and the user. While each simulation is a separate activity, there is a fairly standard set of interrelated activities that always take place. Simulation, when done correctly, is a process as shown in Figure 4. Even if a simulation project involves only one person, the steps are still relevant.

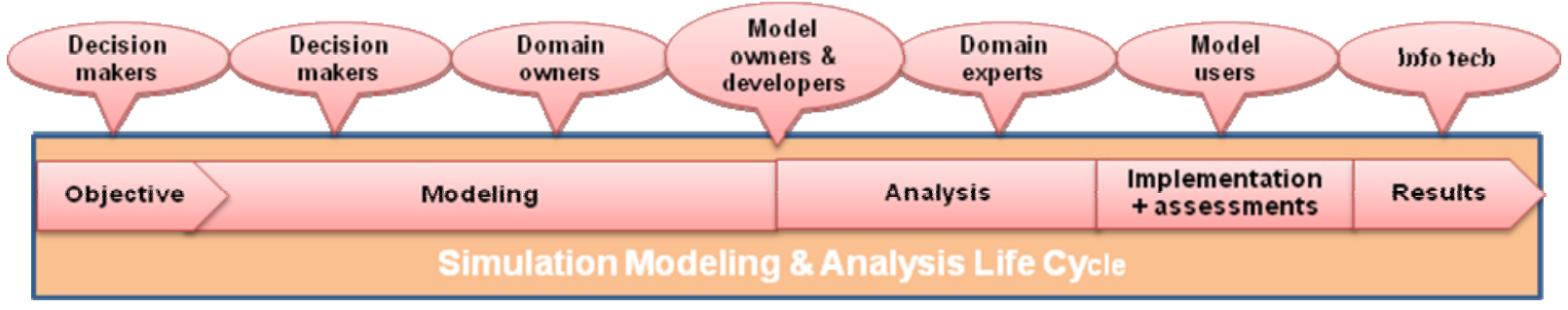

Figure 4: Simulation Modeling and Analysis Life Cycle

Simulation projects involve people, even if one person fills all the roles. These roles include the Developer, Designer, Analyst, Researcher, Investigator, Educator, and Implementer. To work with others effectively, a set of tools for communications is required. Applied Simulation Modeling and Analysis using Flexsim provides a flow diagramming technique (Figure 5) that provides a visual understanding of the simulation. It augments traditional value-stream mapping which falls short of providing the dynamic information required of a simulation.

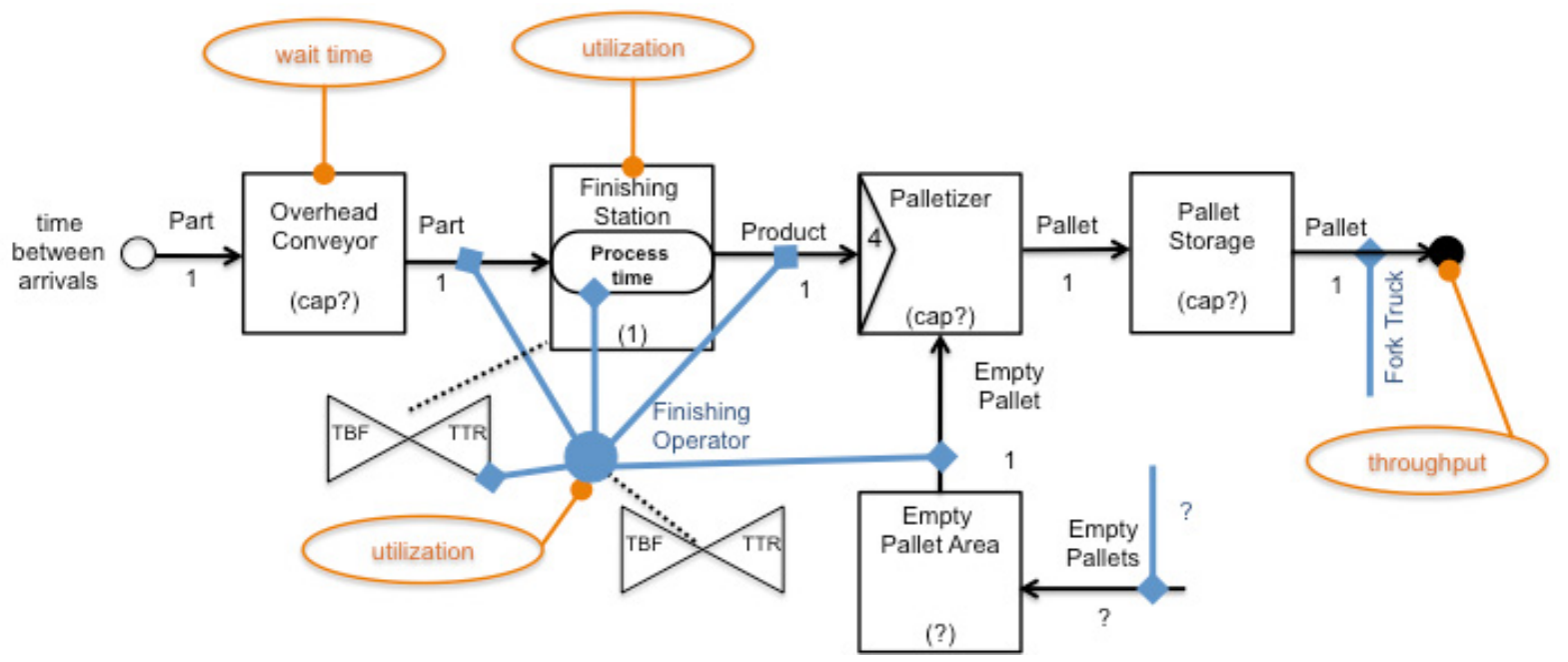

Figure 5: Object flow diagram

Additionally, a project template is provided for documenting simulation objectives, assumptions, and methods.

While textbook exercises can't match real life in many aspects, Applied Simulation Modeling and Analysis using Flexsim provides an approach that comes closer to actual practice. Each exercise requires addressing a problem associated with some operations system such as the frame shop shown in Figure 6 where decisions about staffing have to be resolved. The exercise contains background information about the particular situation, a problem statement (usually presented from a senior management perspective), and operational information. The expected results involve a solution statement. 


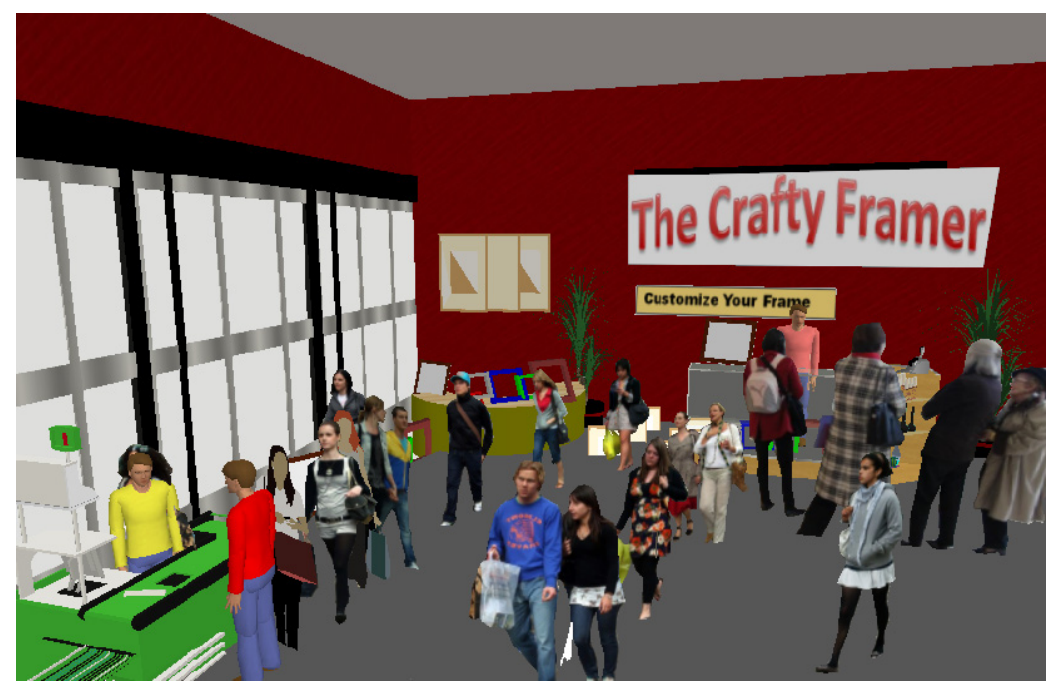

Figure 6: Frame shop exercise

While working on the exercise, the student has to interpret the situation, determine what should be simulated, and analyze the results. The solution statement often requires interpretation of the results rather than simply presenting a numerical answer. Discussion topics for each exercise are intended to act as a guide for application techniques such as determining the simulation scope, assumptions, where to place operational data, and what logic should be employed.

\subsection{Simulation Software has Become Easy to Use}

"Ease of Use" is a common and possibly over-used term to attempt to describe how easily simulations can be built. But Ease of Use can be a two-edged sword. Simulation professionals and educators know that simulation is neither a black box nor a silver bullet and that its incorrect use can lead to inaccurate conclusions and a lack of confidence in the technology. Simulations that are built "automatically" may not be correct. They can lead to an embarrassing situation when a simulation user can't explain why the simulation returned the results it did or what assumptions were build into the logic.

Despite the cautions however, Ease of Use can be used effectively by an educator to create more time in the classroom to focus on application issues and relevant theory and less time teaching software. When an application is easy to use, such as with Flexsim, students are more likely to explore the application capabilities themselves. Being able to work directly in a complete 3D environment and modify simulation objects using such resources as Google 3D Warehouse, students remain interested and eager to learn.

Applied Simulation Modeling and Analysis using Flexsim, coauthor Allen Greenwood of Mississippi State University, has indicated that by switching to Flexsim he has seen a couple of advantages. Most importantly, less class time is used to teach the software. This ease of use advantage means that students are able to work at a higher level of application complexity after a shorter period of time. Additionally, the functional richness of Flexsim has meant that at any point in time in the course he has been able to address more complex application issues. These insights are shown in Figure 7.

Software ease of use can also be used to quickly immerse students in applying simulation without any training in the application language.

Chapter 3 of Applied Simulation Modeling and Analysis using Flexsim contains pre-built simulations that simulate various operations with a problem to be addressed. Students need only open the simulation and interact with it using a custom interface. Figure 8 shows a roller coaster ride example where the student is challenged to maximize profit. Decisions on the number and capacity of cars as well as the staffing levels throughout the day have to be made. Students must also comment on trade-offs between staffing levels and the length of time a customer waits. 


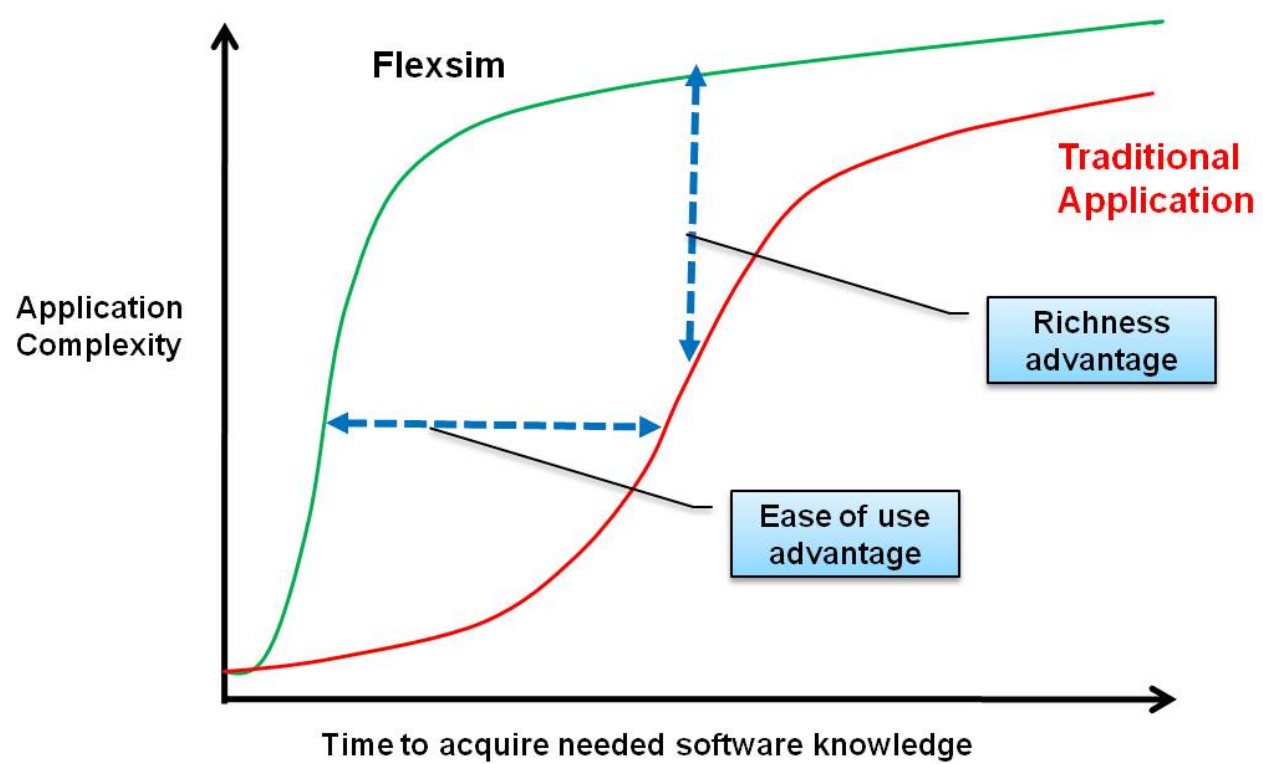

Figure 7: Ease of use classroom advantage

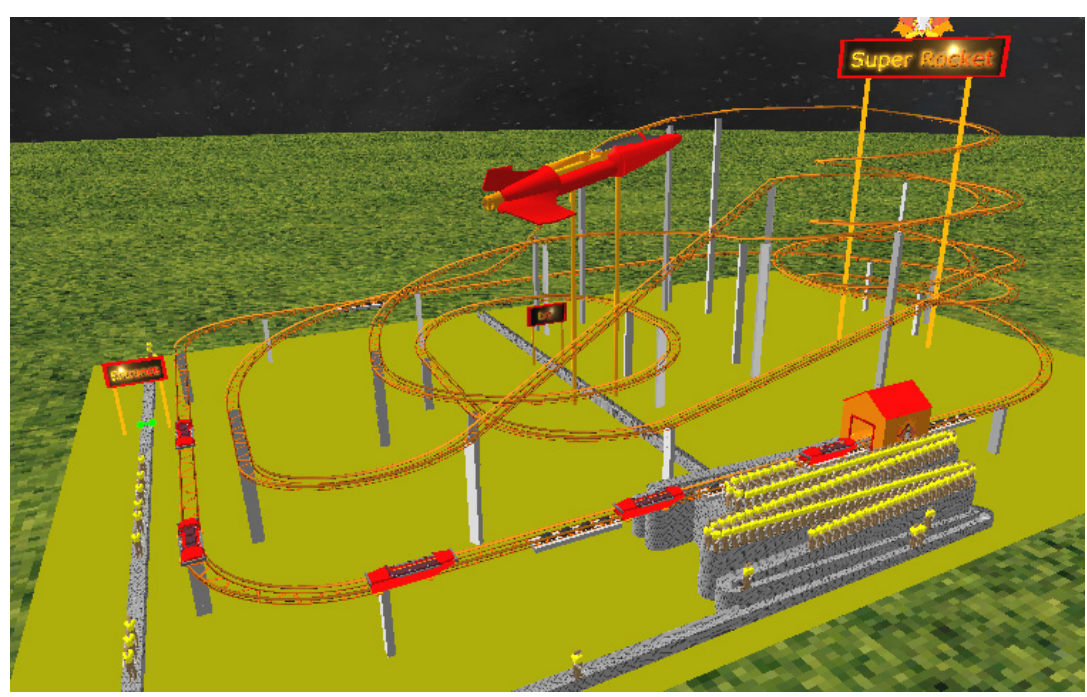

Figure 8: Roller coaster exercise

Other exercises involve checkout lines at a supermarket, improving logistics for getting supplies to outposts, maximizing throughput on a bottling line when product sizes change, evaluating competing lean manufacturing proposals, and optimizing the schedule for a pie factory.

After working with these interesting and visually vibrant simulations, students are motivated to start building their own simulations.

\subsection{Basic Theory is Still Relevant But Must Relate to Application}

Statistical theory provides the backbone to simulation efforts. However, for students to stay focused on simulation principles, the theory should be presented in a way that relates directly to the application of simulation. Applied Simulation Modeling and Analysis using Flexsim addresses this issue in Chapters 9, 10 and 11 . 


\section{Greenwood and Beaverstock}

Chapter 9 covers the topic of modeling randomness and explores how input data for a simulation should be analyzed and used. Students are able to use ExpertFit, the statistical analysis tool developed by Averill Law, which is included with the student license of Flexsim. The chapter also discusses how random numbers and random variates are generated in a simulation and how they can affect the results.

The chapter on output analysis takes advantage of Flexsim's experimenter functionality to give students an opportunity to correctly design simulation scenarios and use statistical methods to analyze the results. The book also teaches the application fundamentals of determining the correct run length for accurate simulation analysis. Through examples, the impact of incorrectly selecting the length of a simulation run is shown. Students learn what to do when they are simulating terminating or non-terminating systems.

Simulating equipment or system reliability is discussed in Chapter 11. Reliability has a significant impact on the performance metrics for a system. It also plays an important role in determining the location and size of any material accumulation points, which is critical for establishing lean production systems.

In practice, students will be faced with acquiring reliability data and correctly using it in simulations. Modern data collection systems provide new insight into when and how machine failures occur. Students use Flexsim's capability to simulate downtimes that are based on a particular state of a machine or system. The ability to simulate competing downtimes in the same equipment is also part of the exercises.

\subsection{Simulation Applications have Broadened in Scope}

Simulation isn't just about manufacturing anymore. Students need to appreciate the wide variety of domains in which simulation is applied. Exercises in Applied Simulation Modeling and Analysis using Flexsim cover a wide variety of operations and situations. For example, the exercise describing a surgery center involves simulating patients as they interact with various roles in the clinic, such as orderlies escorting patients to the lab area or surgical wing.

There are two topics in particular that are covered extensively in this book that are not normally covered in any depth by other simulation textbooks. The first involves simulating fluid or continuous-state change models. Since many manufacturing, and other systems, contain fluid as well as discrete elements, this book dedicates a chapter to simulating hybrid fluid-discrete systems.

Flexsim has a standard library of objects for simulating fluid processing that can represent a liquid or high-speed solid material flow such as grain or sugar. Students build simulations of a mixing and batching system (Figure 9) and a grain loading facility. They also focus on the fluid/discrete interface common to filling systems.

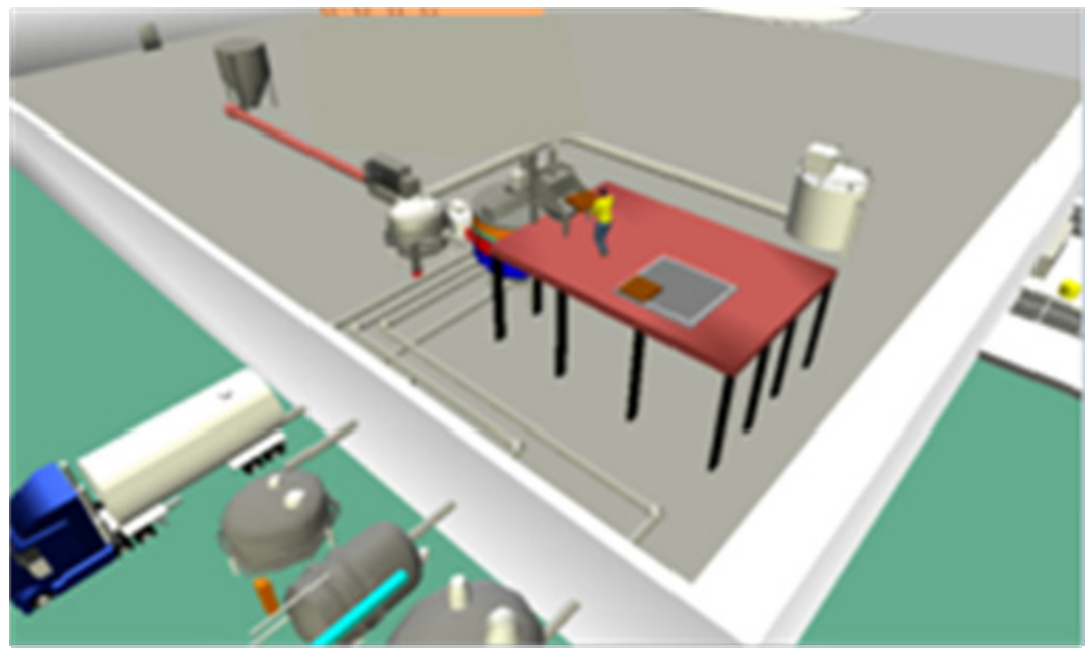

Figure 9: Fluid operations exercise 


\section{Greenwood and Beaverstock}

The second new topic involves scheduling in simulated systems. The schedule in a production plant can be the determining factor in the plant's economic performance. Consequently, simulation is being used more often to determine the impact of schedule changes especially if shared equipment is involved. In the chapter on production scheduling, students simulate the control of production lines that are scheduled by a central controller. Students are faced with decisions concerning where to appropriately measure production and how to handle material that remains on the line once the requisite number of units have been produced. Exercises in both of these chapters do not require programming because of standard Flexsim functionality.

\subsection{Educators can Now have Support Systems}

Developing materials for teaching a subject such as simulation is very time consuming, especially in light of all the other demands on an educator's time. The internet has provided an opportunity for collaboration that can help with the problem.

Flexsim and the authors have joined together to provide support and community web pages for both students and educators. Students have access to downloadable material that supports the textbook. Educators have a password protected site containing support material that includes models that demonstrate application points in the book and completed models for each of the exercises.

This web site is also intended as a community site where educators can exchange lecture slides as well as quiz and test questions and project ideas. Prof Greenwood has already started populating these folders with material from his teaching experience. Educator workshops are also being scheduled to provide additional exposure to this book and the teaching of applied simulation.

Applied Simulation Modeling, and Analysis using Flexsim is the newest step in Flexsim's commitment to simulation education. Flexsim has, and continues, to provide fully functional academic licenses to students engaged in simulation projects and research efforts.

\section{THE BOTTOM LINE FOR CHANGE}

Simulation has always been on the forefront of technology. In the early years of simulation, computing power slowed its application and use. Now advances in software structure and computers have allowed the use of simulation to grow. The opportunity to demonstrate that simulation can indeed deliver as a problem solving tool will depend on how well users are educated in its application.

Applied Simulation Modeling and Analysis using Flexsim enhances the traditional approach to simulation education and provides students and educators both with a fresh view to the professional practice of simulation.

\section{REFERENCES}

Beaverstock, M, A. Greenwood, E. Lavery, and W. Nordgren. 2011. Applied Simulation, Modeling and Analysis using Flexsim. 1st ed. Oren, Utah: Flexsim Software Products, Inc.

\section{AUTHOR BIOGRAPHIES}

ALLEN GREENWOOD is a Professor of Industrial and Systems Engineering at Mississippi State University (MSU) teaching systems simulation, enterprise systems engineering, and project management. His research interests/expertise include the design and analysis of production and project systems; simulation modeling, analysis, and optimization; and the design and application of decision-support systems. His professional experience spans a wide variety of domains -- engineering design and development (military aircraft and aerospace), manufacturing and production systems (military aircraft, shipbuilding, automotive, textile fibers, healthcare, and electrical systems), and project management. He has authored or coauthored over 100 creative works, including journal and conference papers, technical reports, software programs, etc. Allen received his B.S.I.E, M.S.I.E, and Ph.D. (Management Science) degrees from North 
Carolina State University, University of Tennessee, and Virginia Tech, respectively. Prior to joining MSU, he held positions at American Enka Company, General Dynamics Corporation, Virginia Tech, Northeastern University, and the American University of Armenia. His email is greenwood@ise.msstate.edu.

MALCOLM BEAVERSTOCK joined Flexsim as a consultant after a 40 year career of applying advanced control and simulation to industrial problems. During his 13 years with General Mills, he developed and led their simulation program which was involved with more than 300 projects that resulted in significant savings attributed to the use of simulation. Following graduate studies, Malcolm joined UniRoyal Chemical as manager of their advanced control group implementing digital control systems. During his 17 years at the Foxboro Company he managed various technology groups and established the systems research department that resulted in the Foxboro I/A control system. As Vice President of Automation Technology, he initiated work into model-based control applications. Malcolm holds a Bachelor's degree in Chemical Engineering and Labor Relations from MIT and a PhD from Cornell University in Chemical Engineering and Computer Science. He's the author of more than 200 papers on the application and use of advanced technologies. His email is mal.beaverstock@flexsim.com. 